This item was submitted to Loughborough's Research Repository by the author.

Items in Figshare are protected by copyright, with all rights reserved, unless otherwise indicated.

\title{
Digital image processing and illumination techniques for yarn characterization
}

PLEASE CITE THE PUBLISHED VERSION

http://dx.doi.org/10.1117/1.1902743

\section{PUBLISHER}

Copyright 2005 Society of Photo Optical Instrumentation Engineers.

\section{VERSION}

VoR (Version of Record)

\section{PUBLISHER STATEMENT}

This work is made available according to the conditions of the Creative Commons Attribution-NonCommercialNoDerivatives 4.0 International (CC BY-NC-ND 4.0) licence. Full details of this licence are available at: https://creativecommons.org/licenses/by-nc-nd/4.0/

\section{LICENCE}

CC BY-NC-ND 4.0

\section{REPOSITORY RECORD}

Ozkaya, Yasar A., Memis Acar, and Michael R. Jackson. 2019. "Digital Image Processing and Illumination Techniques for Yarn Characterization”. figshare. https://hdl.handle.net/2134/19368. 


\title{
Digital image processing and illumination techniques for yarn characterization
}

\author{
Yasar A. Ozkaya \\ Memis Acar \\ Mike R. Jackson \\ Loughborough University \\ Mechanical Engineering Department \\ Mechatronics Research Group \\ Loughborough, Leics, LE113TU \\ United Kingdom \\ E-mail: y.a.ozkaya@lboro.ac.uk
}

\begin{abstract}
This paper describes various illumination and image processing techniques for yarn characterization. Darkfield and back-lit illuminations are compared in terms of depth of field tolerance and image quality. Experiments show that back-lit illumination is superior in terms of depth of field tolerance and contrast. Three different back-lit illumination configurations are studied: one simply employing a light source placed behind the yarn, the other incorporating a field lens to increase the light intensity passing through the aperture, and the third using a mirror placed at $45^{\circ}$ to the optical axis to enable imaging of two orthogonal views of the yarn core. Problems in defining the hair-core boundaries in high resolution yarn pictures are addressed and a filtering process is introduced for back-lit images. A comparison of the diameter and diameter coefficient of variation percentage measurements for different illumination and image processing techniques is given for several yarn samples. The data are also correlated with Premier 7000 diametric irregularity tester and Uster Tester 3 irregularity measurements. (C) 2005 SPIE and IS\&T. [DOI: 10.1117/1.1902743]
\end{abstract}

\section{Introduction}

Irregularity is probably the most important yarn characteristic affecting the processes subsequent to yarn spinning and the end fabric properties. An irregular yarn suffers more breakages in spinning, winding, warping, as well as weaving and knitting. ${ }^{1}$ This will reduce the efficiency and increase the cost of all these processes. Irregularity in a yarn also creates appearance faults in fabrics due to uneven yarn diameter and different dye absorption levels. ${ }^{2}$ Measuring yarn irregularity has been an important issue for the textile instrument developers and researchers. Among numerous methods developed to measure yarn irregularity, two methods are commonly used today in the textile industry: one employing optical sensors to measure the diametric irregularity and the other uses capacitive sensors to measure the variation in mass. Charge-couple device (CCD) sensors are likely to replace conventional optical sensors owing to much higher resolution capabilities and versatility. Figure 1 shows a yarn picture where various hairiness types

Paper 04134 received Jul. 15, 2004; revised manuscript received Oct. 14, 2004; accepted for publication Nov. 15, 2004; published online May 12, 2005 $1017-9909 / 2005 / \$ 22.00$ (C) 2005 SPIE and IS\&T. and the diametric irregularity can be seen. It can be argued that many yarn characteristics including hairiness, diameter, and their variations can be extracted simultaneously by employing suitable image acquisition and processing techniques. Numerous researchers have introduced different illumination and image processing techniques for yarn characterization. However, there is a lack of research on the comparisons of these different techniques and this paper aims to address this issue.

One of the early methods used to obtain diametric irregularity was to compare the amount of light measured by a photocell before and after insertion of a yarn; the difference being proportional to the diameter. ${ }^{3}$ The photocell readings were calibrated using wires with known diameters. This technique was, however, affected by the surface hairs resulting in a significant and inconsistent rise in the diameter measurements. Modern commercial testers such as Zweigle G580 and Premier $7000^{5}$ rely on a similar principle. These testers have resolutions of 2 and $1 \mathrm{~mm}$, respectively. Another common method was direct measurement of yarn diameter manually, using magnified images obtained from a microscope or the projection of the shadow on a

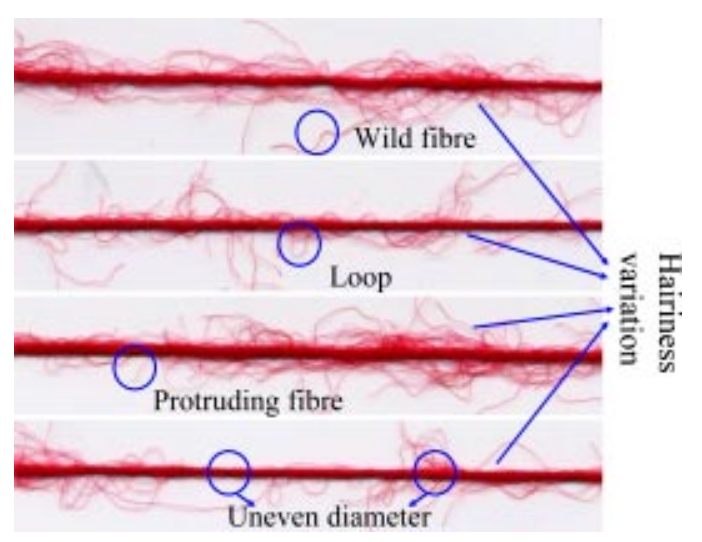

Fig. 1 Pictures of a yarn showing hairiness and diametric irregularity. 


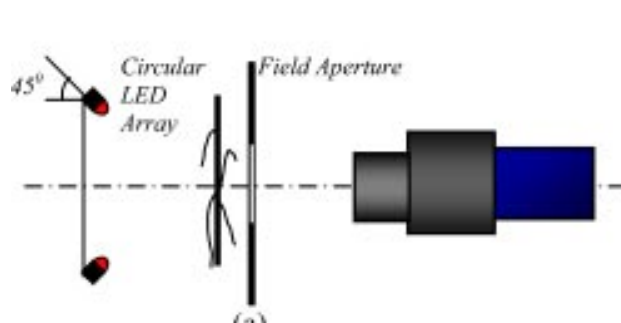

(a)

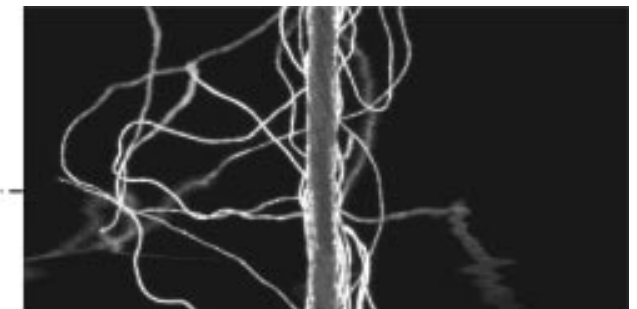

(b)

Fig. 2 (a) Dark-field illumination arrangement and (b) a yarn image acquired using this setup.

screen through some magnifying lenses. ${ }^{6}$ However, this method was not favored due to its tedious nature. An interesting approach was adopted by van Issum and Chamberlain $^{7}$ where they photographed a running yarn in such a way that a considerable length of the specimen passed before the camera while the shutter was open. The resultant picture was a uniform profile with no hairs but with blurry edges. By examining the edge profiles, they calculated minimum and average diameters of the yarn section. Another approach to determine the diametric irregularity is by means of optical filtering. ${ }^{8,9}$ Rodrigues et al. ${ }^{25}$ explain that by using a special filtering mask with coherent dark-field imaging, it is possible to separate the hairs from core. A similar technique that incorporates a special lowpass filter is adopted by the Keisokki Tester. ${ }^{10}$

Chu and Tsai ${ }^{11}$ addressed one of the main restrictions in traditional optical methods that use photoelectric sensors as the light source emitting inhomogeneous intensity. They introduced an area compensation method to overcome this problem. Zweigle ${ }^{4}$ also addressed the issue in Zweigle G580 using two sensors first one measuring the light intensity partly blocked by yarn and the other a reference unblocked intensity value. On the other hand, the transmission of light through yarns, monofilament yarns in particular may lead to smaller diameter readings obtained from optical sensors as reported by Wulfhorst and Bergmann. ${ }^{12}$

One of the major concerns in diameter measurement is the cross-sectional profiles of yarns seldom being circular. Slater ${ }^{1}$ indicates that the asymmetrical yarn sections would tend to be presented to the light source in preferential direction of alignment, rather than in a random manner, because of the guide rollers, etc., of the transport mechanism. A common method to minimize the asymmetry problem is to measure the diameter from two orthogonal views of the yarn section. ${ }^{2}$ Chu and Tsai ${ }^{13}$ used a sensor device with two incident beams of light perpendicular to each other. They found that the coefficient of variation percentage (CV\%) values calculated from elliptical diameters were smaller than those obtained from single view diameters and only slightly higher than the Uster's CVm\% (CV\% of yarn mass) values.

Computer vision techniques have been used for more than 20 years for yarn characterization research. Several studies have been reported using computer vision to measure one or more characteristics simultaneously such as hairiness, ${ }^{14-17}$ diameter, ${ }^{8,17-19}$ twist, ${ }^{16-17}$ and density. ${ }^{20}$ Recently, some commercial testers such as Uster Tester 4SX and Lawson Hemphill YPT have introduced testing modules with CCD sensors. Computer vision probably provides the widest range of possibilities for hairiness assessment enabling both simulation of current indices and development of new ones.

It is evident that the light and the illumination arrangement together play an important part in the acquisition and overall pre-processing of yarn images. The illumination methods in the literature used for yarn imaging can be categorized in three main groups, which are back-lit (e.g., Zweigle G565), front-lit (e.g., Cybulska ${ }^{16}$ ), and dark field (e.g., Uster Tester Hairiness Attachment) illuminations. Back-lit illumination is the most common method especially for diameter measurement.

The main problem in yarn image processing is the definition of the boundaries between the core and the surrounding hairs. For back-lit and front-lit images, the most common approach is to set a certain threshold value and identify the longest interval of yarn pixels as the core. ${ }^{15,17,18,21}$ However, the diameter measurements will strongly be affected by this threshold level. ${ }^{12}$ Further, when

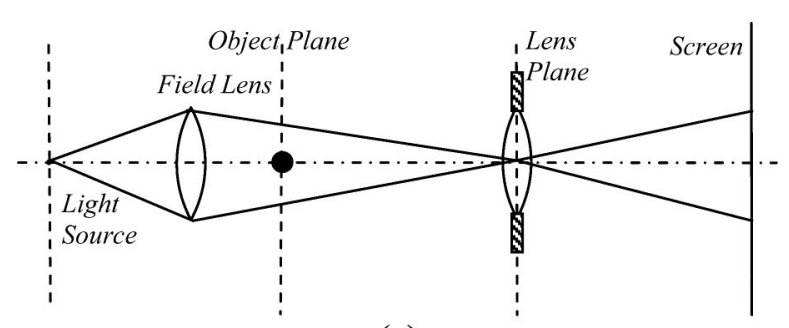

(a)

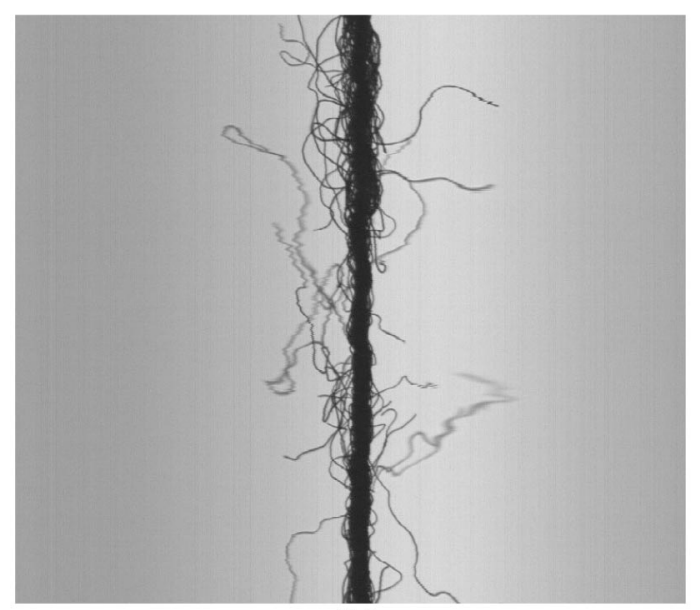

(b)

Fig. 3 (a) Field lens arrangement and (b) yarn image acquired using the field lens setup. 


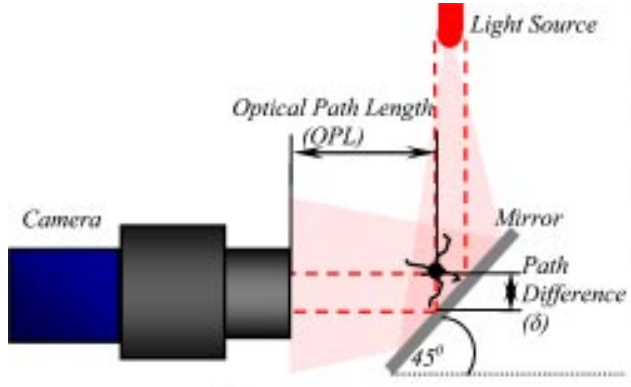

(a)

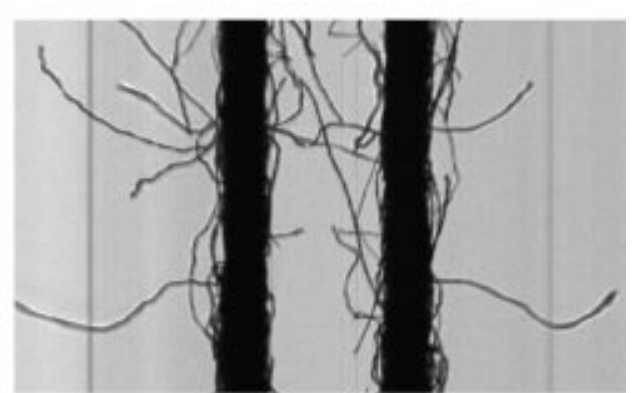

(b)

Fig. 4 (a) Arrangement for imaging of two orthogonal views and (b) image of two orthogonal views of a yarn.

using high resolutions, the assumption that the longer duration signals represent the core can sometimes cause hairs lying along the scan line to be identified as the core. At high resolutions, there is also generally no significant change in the intensity of the CCD signal between highly dense surface fibres and the core. This increases the core diameters if a single threshold is applied. Cybulska ${ }^{16}$ presented a technique to define core boundaries for front-lit yarn images. The method initially found the core edges from the connected intervals of foreground pixels having the greatest length by scanning each line in the image perpendicular to the core axis. These initial boundaries are then corrected according to some predefined curves along which points generating the edge of the yarn core are assumed to be randomly distributed.

This paper describes and compares various illumination methods used for yarn imaging in conjunction with a CCD device. Eight different adaptive thresholding algorithms are tested on back-lit yarn images and the results are discussed. A two-level adaptive thresholding method is described which enables detection of defocused fibers while identifying the isolated background pixels around the yarn core. A filtering process is also introduced in order to minimize the effect of the hairs surrounding the core on the diameter measurements. The diametric variations are correlated with the diametric variations from Premier 7000 and the mass variations from Uster Tester 3 for several yarn samples.

\section{Experimental Setup}

A Dalsa Spark 2048-pixel line scan camera with a $100 \mathrm{~mm}$ macrolens set at 1:1 magnification is used for image acquisition. The maximum line rate of the camera is $18.8 \mathrm{kHz}$. The images are transferred to a P3-800 PC through a Viper Digital frame grabber. The pixel size of the camera is 14 $\mu \mathrm{m} \times 14 \mu \mathrm{m}$ and the fill factor is $100 \%$. The line acquisition is triggered using an optical encoder attached to the yarn transfer system.

The yarn transfer speed can be set to a speed of up to 80 $\mathrm{m} / \mathrm{min}$ at 14 scans $/ \mathrm{mm}$ resolution. This resolution can be increased by decreasing the yarn transfer speed. Images are processed using WIT 7.1 image processing software and C programming language.

For yarn illumination, two basic illumination types are tested which are dark-field and back-lit illuminations. The dark-field illumination arrangement is similar to the one used by Bamforth et al. ${ }^{22}$ for the lace scalloping system. Forty-six LED lights are placed around a ring with a 55 mm radius. Some improvements are found necessary over Bamforth's design for yarn illumination such as rotating the LED lights $45^{\circ}$ toward the optical axis in order to increase the intensity of light falling onto yarn as shown in Fig. 2. Further, a field aperture placed between the yarn and the camera is found necessary, which provided a significant enhancement on the image background. The size of the field aperture is set to $30 \mathrm{~mm}$, which is slightly larger than the field of view $(28 \mathrm{~mm})$. An important drawback of this illumination was the poor light intensity enabling a maximum shutter speed of $10^{2} \mathrm{~s}^{-1}$, which is not adequate to achieve the $18.8 \mathrm{kHz}$ maximum line rate of the camera.

For back-lit illumination, the simplest case was placing the yarn between a light source and the camera. The background formation in back-lit illumination is due to the blurring of the light source and the nature of the shadow of the yarn is governed primarily by the diffraction effect of the fibers. The effects of light source parameters such as the size and the wavelength and the distance between the yarn and the light source are studied in detail based on the Fresnel diffraction theory. ${ }^{23}$ (Figure 6 shows an image acquired using a $20 \mathrm{~W}$ tungsten filament bulb placed $550 \mathrm{~mm}$ from the yarn.) At the maximum light intensity, the shutter speed could be set to as high as $2 \times 10^{4} \mathrm{~s}^{-1}$, which is adequate to achieve the maximum line rate of the camera.

In order to increase the light energy arriving to the sensor in back-lit illumination, a field lens is tested as shown in Fig. 3(a). The basic principle in this arrangement is to focus the light source to the aperture of the camera lens. Figure 3(b) shows an image captured using a halogen lamp and a $30 \mathrm{~mm}$ field lens. It can be seen that the background was not quite uniform in the images acquired using this setup because of the nonuniformity of the light source. However, this can be enhanced using flat field correction, which is implemented simply by subtracting the background image from the yarn image or by dividing the intensities of every single pixel by the corresponding background intensity and weighing by a certain factor. The allowable shutter speed in this setup was quite satisfactory allowing the maximum line rate of the camera even at $1 / 5$ th of the maximum light intensity.

Since the shape of the yarn core is not always circular, measurement of the yarn diameter and the diametric irregularity from a single view might be erroneous. A similar arrangement to that described by Jackson et $a l^{24}$ has been implemented as shown in Fig. 4(a). An important problem with this arrangement is that if the camera is focused to one 
side of the yarn, then the other side will be out of focus by a distance of $\delta$ as shown in Fig. 4(a). To equalize the optical path lengths for both sides, the camera is focused to OPL $+\delta / 2$. However, in this case the images of both sides will have a defocusing error corresponding to a distance of $\pm \delta / 2$. In order to minimize the defocusing error, $\delta$ is kept as low as possible, at $\sim 1.4 \mathrm{~mm}$, assuming that the core diameter is always below this value. This distance allowed separation of two orthogonal views in the images for the entire range of yarns used for the experiments. Further, the light source is placed $\sim 700 \mathrm{~mm}$ away from the mirror to minimize the edge blurring due to defocusing. Based on Fresnel diffraction calculations the error for a $400 \mu \mathrm{m} \mathrm{di}$ ameter at $0.7 \mathrm{~mm}$ defocusing will be $12 \mu \mathrm{m}$ which can be omitted due to the effect of digitization at the magnification used. If a larger $\delta$ is necessary, one solution could be inserting a glass medium to the optical path of one view in order to equalize the optical path lengths as suggested by Millman. ${ }^{25}$ Figure 4(b) shows the image of an Ne10 (Tex 59) $100 \%$ cotton yarn acquired using this setup.

Figure 5 shows the defocus profiles of a $45 \mu \mathrm{m}$ polypropylene fiber for dark-field, back-lit, and field lens illuminations. It can be seen that simple back-lit illumination is significantly superior to others in terms of depth of field tolerance and the fiber is clearly visible even at $40 \mathrm{~mm}$ defocusing whereas the fiber is barely detectable at 5 and 6 $\mathrm{mm}$ for dark-field and field lens illuminations, respectively. Depth of field tolerance is especially important for hairiness measurement.

\section{Processing of Back-Lit Yarn Images}

The histogram (gray level distribution) of a back-lit yarn image has a bimodal shape as shown in Fig. 6. The first peak in the histogram belongs to the core pixels along with the in-focus hairs which appear dark in a back-lit image. The second and larger peak arises from background pixels, which gets narrower for increasing uniformity of the background, allowing a clearer distinction from the first peak. There are also some pixels falling between these two peaks that come from two different sources, which are (i) out-offocus hairs and (ii) isolated background pixels in between dense fibers occurring especially in close vicinity of the core. Figure 7 shows a horizontal image profile where these two types of pixels can be seen.

In order to separate the background from the yarn pixels, we tested eight common adaptive thresholding algorithms in the literature. These methods include the global methods of Otsu, ${ }^{26}$ Kittler and Illingworth, ${ }^{27}$ Kapur et al. ${ }^{28}$ and Abutaleb $^{29}$ and local methods of Niblack, ${ }^{30}$ Sauvola and Pietaksinen, ${ }^{31}$ Bernsen, ${ }^{32}$ and Yanowitz and Bruckstein. ${ }^{33}$ Figure 8 shows the outputs of these methods for a yarn image. For the algorithms that require additional parameters the optimum input values are dictated by trial and error.

The local thresholding methods were more successful in terms of detecting defocused hairs while correctly classifying the isolated background pixels. Nevertheless, the actual yarn picture is altered in the methods of Niblack, ${ }^{30}$ Sauvola and Pietaksinen, ${ }^{31}$ and Bernsen, ${ }^{31}$ all of which identify the core region as the background. This might be helpful if the hairiness is of interest only. The method of Yanowitz and Bruckstein $^{33}$ on the other hand was quite successful in

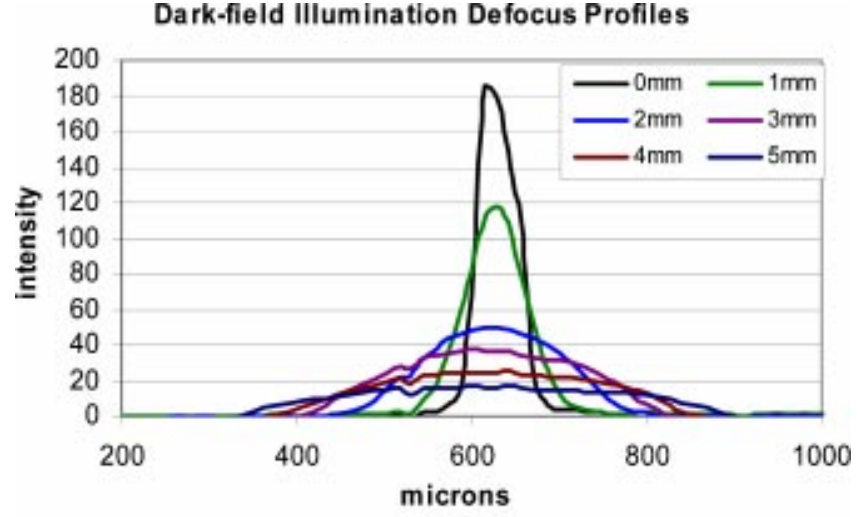

(a)

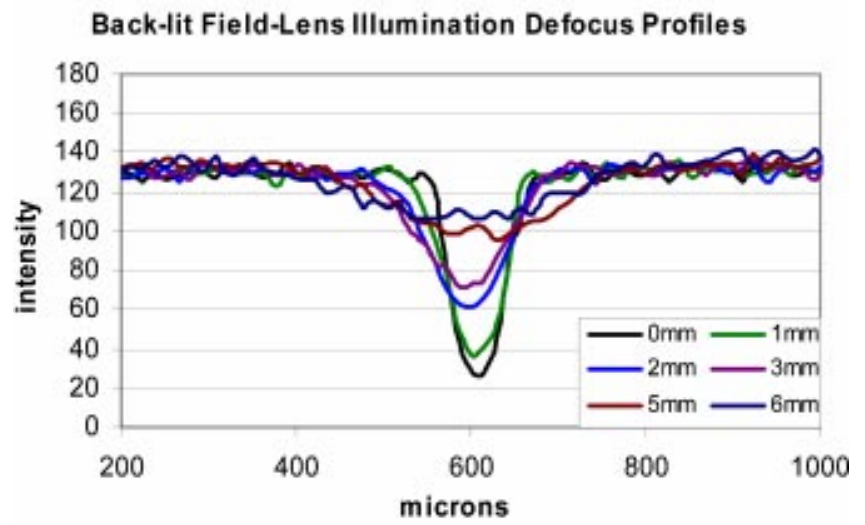

(b)

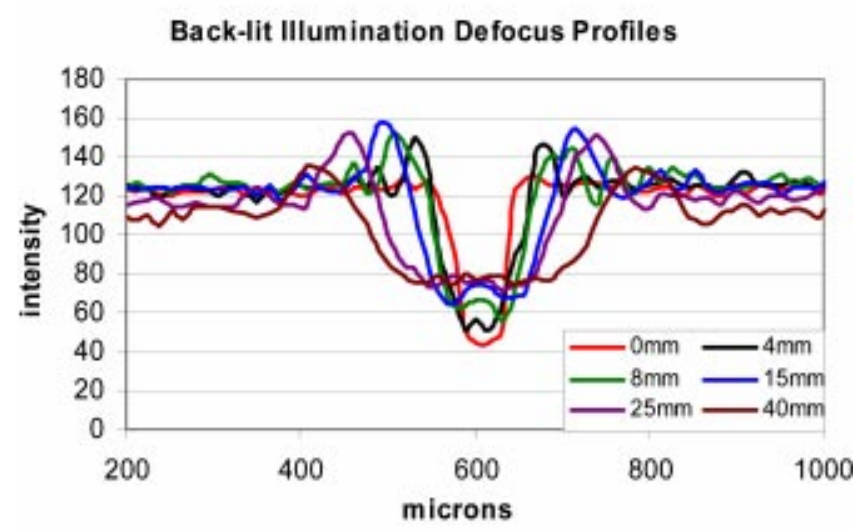

(c)

Fig. 5 Profiles of a $45 \mu \mathrm{m}$ polypropylene fiber under (a) dark field, (b) back-lit with field lens, and (c) back-lit illuminations for varying defocus distances.

terms of lack of background noise and classification of defocused hairs and isolated pixels. However, the ghost removal process involved in this technique erased some core regions as can be seen in Fig. 8(i). Further, this technique requires too many input parameters. Locally adaptive thresholding techniques also require more processing times compared to the global methods as can be seen in Table 1.

Owing to the good contrast and background uniformity in back-lit yarn images, global thresholding methods were 


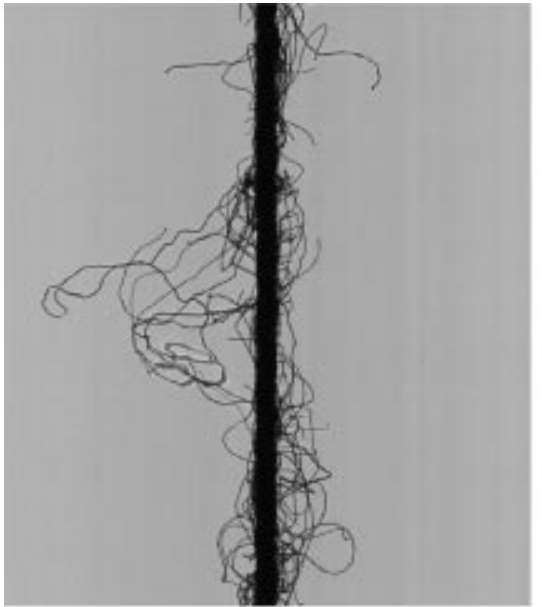

(a)

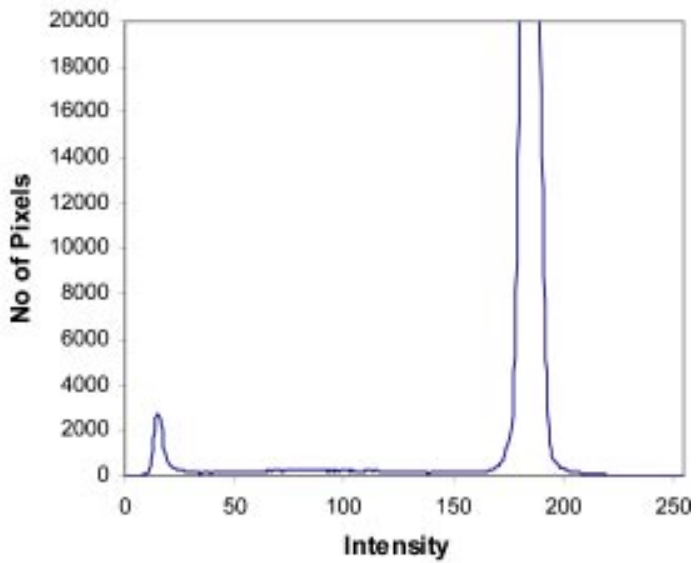

(b)

Fig. 6 A back-lit yarn image and its histogram.

quite adequate in terms of separating the background from the yarn pixels. However, the problem with using a single threshold level is that if the threshold approaches the background intensity, the isolated pixels, especially those around the core, are more likely to be identified as yarn pixels. On the contrary, when the threshold approaches the foreground region, the defocused hairs tend to disappear. It can be seen that the threshold values found from the methods of Kittler and Illingworth ${ }^{27}$ and Abutaleb $^{29}$ enable detection of defocused fibers, however, the core and the hairs appear thicker compared to other methods. Because of the big difference in number of foreground and background pixels, the entropy based thresholding by Kapur et al. ${ }^{28}$ exhibited an extreme case giving a threshold within the background region of the histogram resulting in excessive background noise. The method of $\mathrm{Otsu}^{26}$ on the other hand gave a threshold value that is closer to the foreground peak resulting in loss of defocused hairs while giving clearer core edges. In order to overcome the contradiction in classification of defocused hairs and isolated background pixels, a two-level thresholding approach is adopted. The first threshold value is ideally selected close to the background peak to separate all yarn regions including out of focus hairs from the background, and the second one closer to the foreground peak in order to identify isolated background pixels.

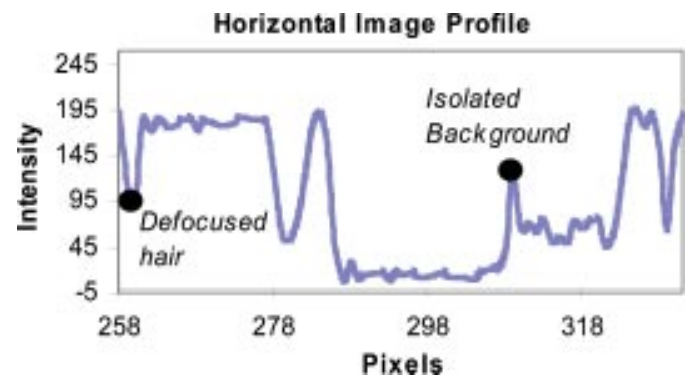

Fig. 7 A horizontal profile showing an isolated background pixel and a defocused hair.
A simple algorithm is implemented that tracks the histogram upward through the $y$ axis, starting from the minimum $y$ value, and for each $y$ value tracks it leftwards parallel to the $x$ axis starting from the pixel intensity having the maximum number of pixels. This tracking continues until a tracking line parallel to the $x$ axis intersects exactly three points on the histogram provided that the distance between the first two points is more than 20 units. This condition check is deemed necessary to avoid three intersection points to be found because of the small fluctuations at the bottom of the histogram and it does not affect the threshold values found. Figure 9 shows this algorithm and selection of the threshold values. The $x$ coordinate of the first intersection point is the bottom point of the background peak and all the intensities above this value belong to the background. The first threshold value is found by subtracting an empirical constant of 10 from this point due to the background noise. The midpoint of the valley between the two peaks is found from the average of the first threshold value and the $x$ coordinate of the second point intersecting the histogram and selected as the second threshold value. Figure 10 shows the images thresholded at these two different levels. It can be seen that the hairs are defined better in the first thresholded image whereas the core edges are clearer in the second thresholded image. The total processing time of the algorithm was around $2 \mathrm{~ms}$.

The core axis is located from the second thresholded image. This is done by first integrating each column for the first 25 rows of the binary yarn image. The integration results in 0 along the columns in the vicinity of the core axis and the hairs lying parallel to the core axis. For hairs extending parallel to the core the interval of zero sums will be shorter than the one corresponding to the core, therefore the longest interval gives the minimum width of the core whereas its center gives the core axis as shown in Fig. 11. Since the hairs perpendicular to the core have diameters less than 25 pixels, the integrations in those regions is always above zero.

One of the methods implemented to locate the core-hair boundaries is based on morphological filtering. ${ }^{17}$ The 

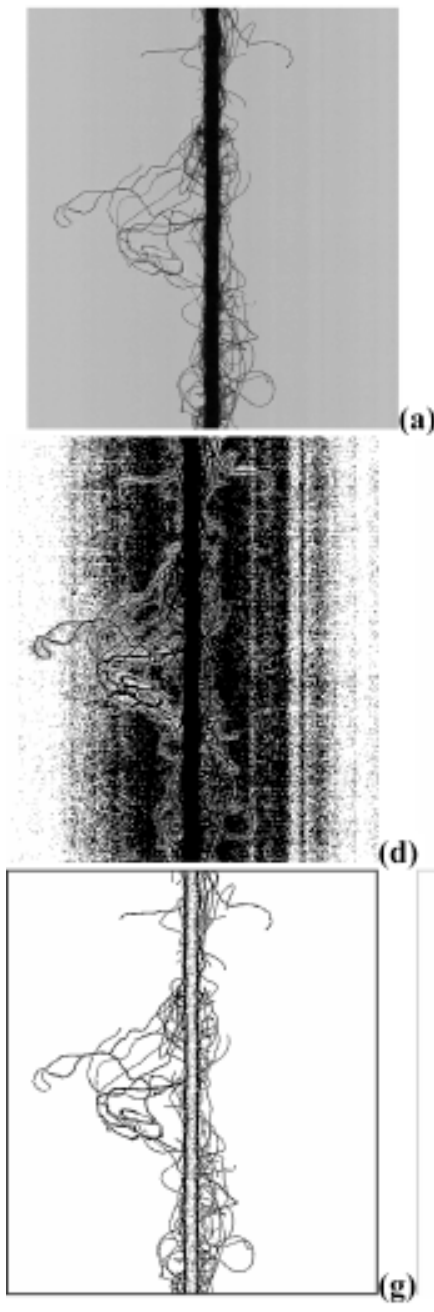
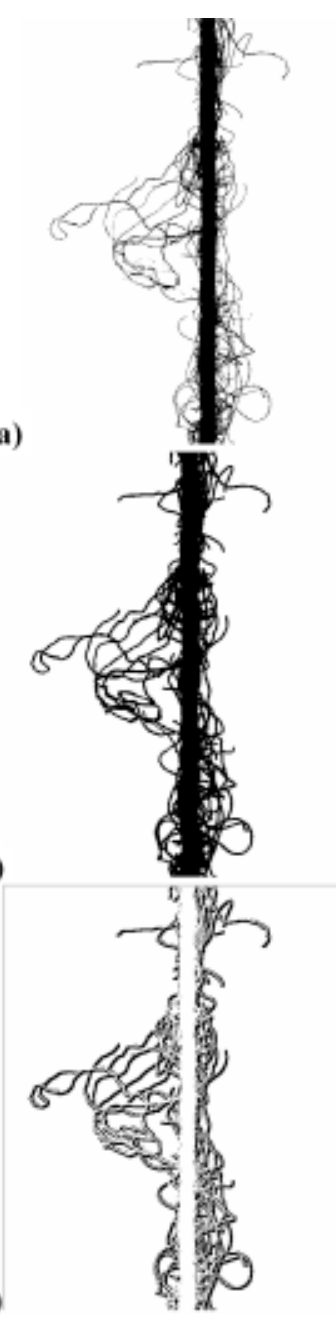

(b)

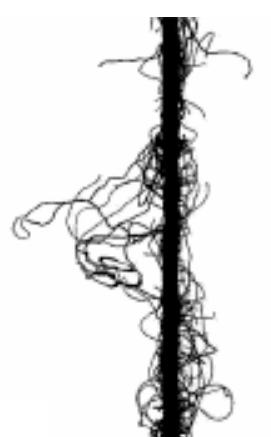

(e)

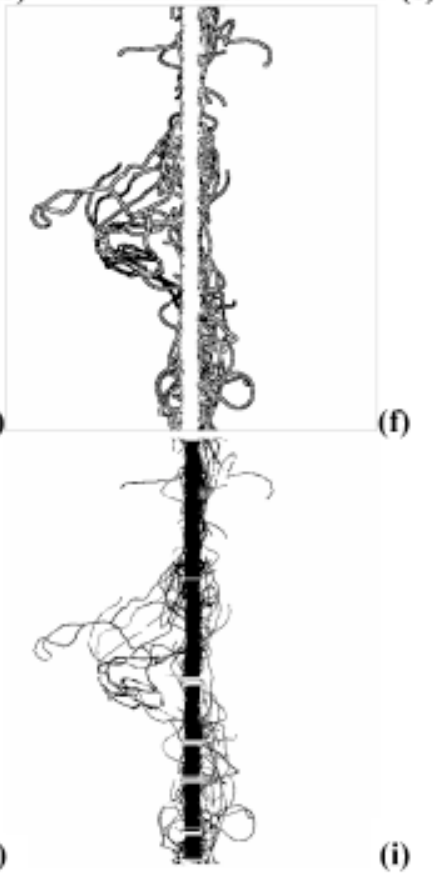

(c)

(f)

(i)

Fig. 8 (a) Original yarn image with uniform background, (b-k) (a) binarized using the methods of: (b) Otsu, ${ }^{26}$ (c) Kittler and Illingworth, ${ }^{27}$ (d) Kapur et al. ${ }^{28}$ (e) Abutaleb, ${ }^{29}$ (f) Niblack $(k=5, n=5 \times 5),{ }^{30}$ (g) Sauvola and Pietaksinen $(k=0.1, n=9 \times 9, R=128),{ }^{31}(\mathrm{~h})$ Bernsen $(L=0.5$, $n=5 \times 5),{ }^{32}$ and (i) Yanowitz and Bruckstein (beta $=1.5$, iterations $=3, T p=5$, edge detection threshold=12). ${ }^{33}$

method described here involves tracking every line in the image in both directions from the core axis perpendicular to it until the first threshold value is reached. Figure 12(b) shows the extracted core through this process. It can be seen that this method overestimates the diameter at many regions because of the fibers protruding from the core as mentioned before. To overcome this problem, a filtering

Table 1 Processing times of different thresholding methods.

\begin{tabular}{lc}
\hline \hline Method & $\begin{array}{c}\text { Processing } \\
\text { time }(\mathrm{ms})\end{array}$ \\
\hline Otsu $^{26}$ & 12 \\
Kitler and Illingworth $^{27}$ & 12 \\
Kapur et al. $^{28}$ & 19 \\
Abutaleb $^{29}$ & 93 \\
Niblack $^{30}$ & 233 \\
Sauvola and Pietaksinen $^{31}$ & 782 \\
Bernsen $^{32}$ & 212 \\
Yanowitz and Bruckstein $^{33}$ & 848 \\
\hline \hline
\end{tabular}

process is applied, which limits the change in diameter if a sudden increase or decrease is observed between successive lines. The parameters for this filtering are determined experimentally through observation of many images and it is found that at 1:1 magnification and 1:1 aspect ratio, displacements of edge boundaries by more than 3 pixels between successive scans were often due to the surface fibers. In such cases, it is found appropriate to limit the increase to 1/7 pixels to ensure that a protruding fiber did not affect the core boundary. Further, if the change was because of a thin or thick place this allowed a gradual change to catch this trend. The maximum displacement can be changed for different magnification and aspect ratio settings. The core boundaries are corrected at two passes, first top to bottom and then bottom to top. Figure 12(c) shows the core profile after this correction process. Figure 12(d) shows the core and the hairs as segmented by the algorithm.

An important drawback of the filtering process is that the change in diameter is limited to around $280 \mu \mathrm{m}$ within a $1 \mathrm{~mm}$ of yarn section. This causes an underestimation of faults like neps (thick sections) and such regions in the yarn increase the measured hairiness rather than the diameter. 


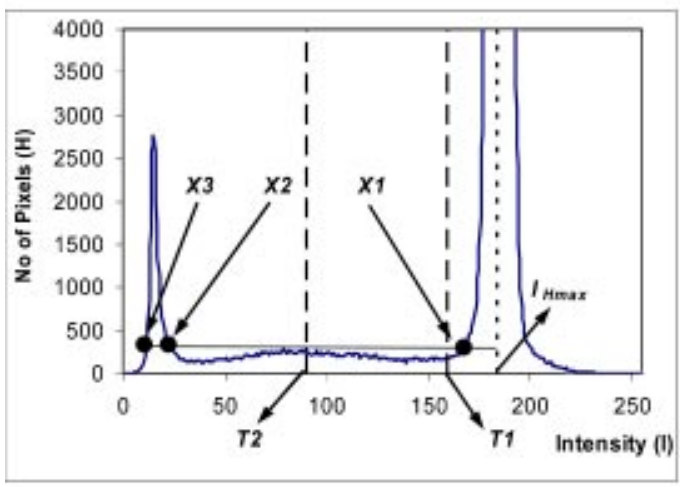

(a)

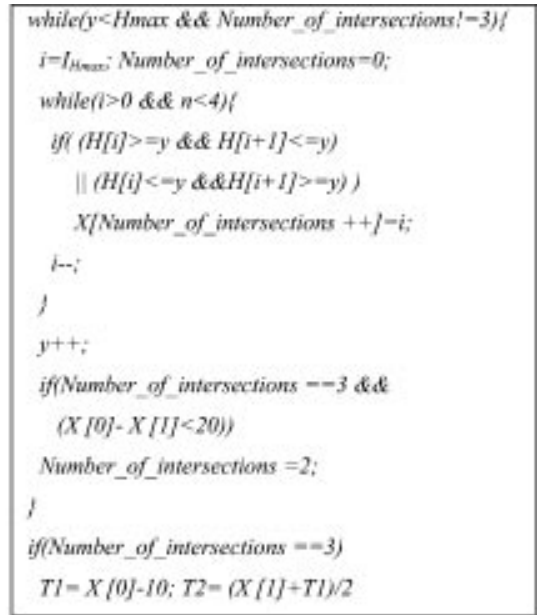

(b)

Fig. 9 (a) Selection of threshold values T1 and T2 from the histogram and (b) the algorithm to determine T1 and T2.

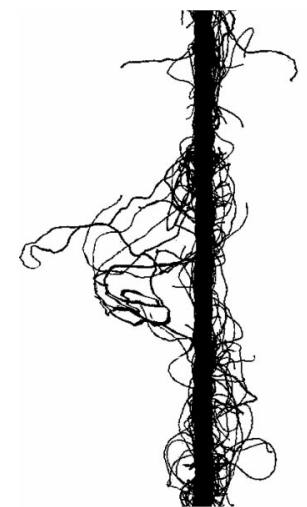

(a)

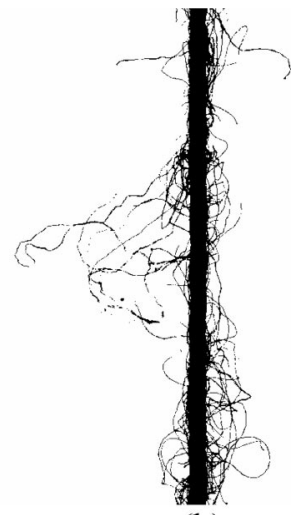

(b)

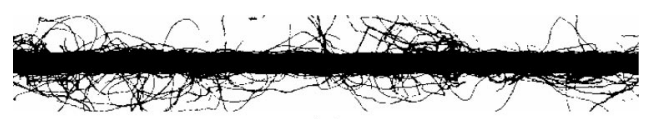

(a)

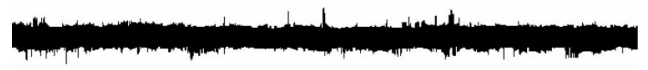

(b)

Fig. 10 Yarn image after applying (a) first threshold (T1) and (b) second threshold (T2).

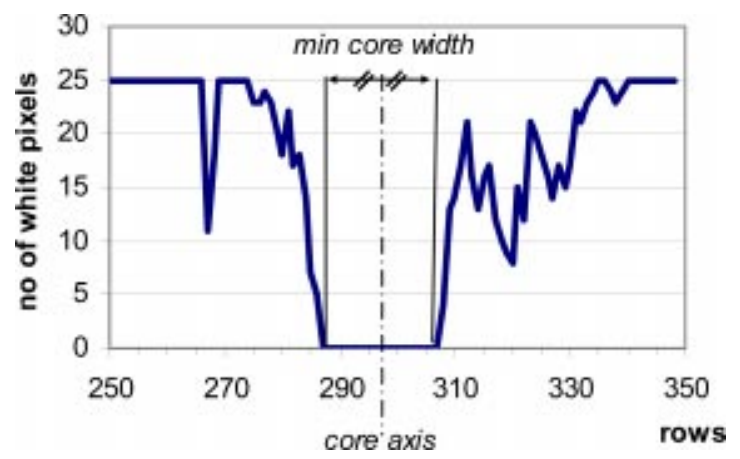

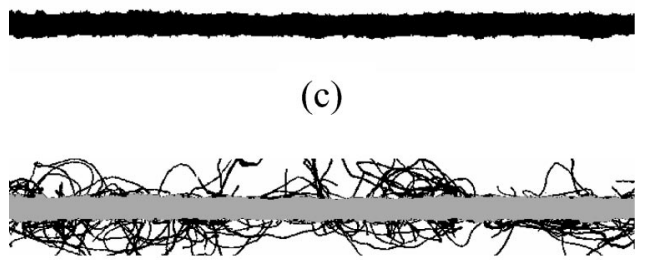

(d)

Fig. 12 Edge tracking method. (a) Second thresholded image, (b) core extracted by tracking, (c) (b) after correction, and (d) (c) overlaid on the first thresholded image showing hairs and the core.

Fig. 11 Integrated columns for the first 25 rows of second thresholded image and location of the core.

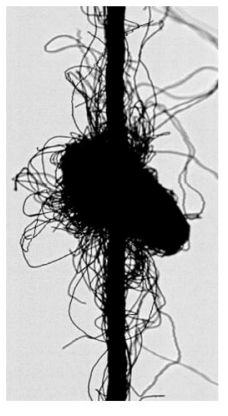

(a)

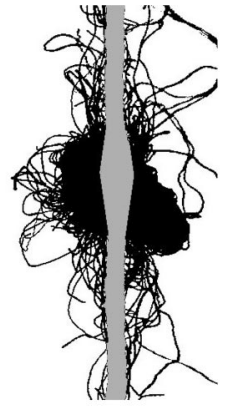

(b)

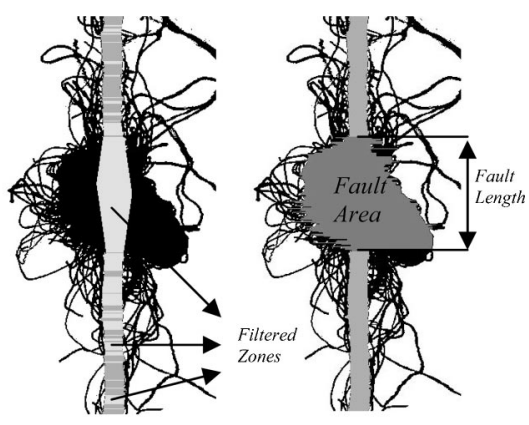

(c)

(d)

Fig. 13 (a) A faulty yarn region, (b) effect of filtering on the fault, (c) identification of fielted regions, and (d) extracted faulty region. 


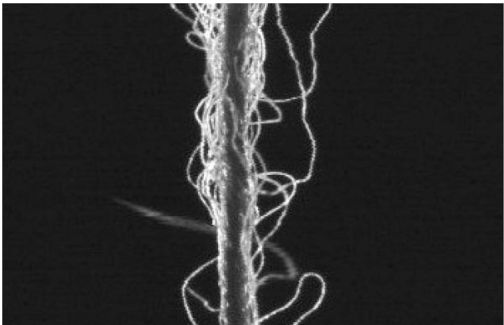

(a)

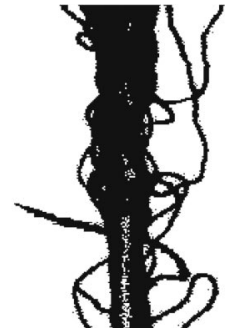

(b)

Fig. 14 (a) A dark-field yarn image (b) and (a) after applying a threshold at 25 .

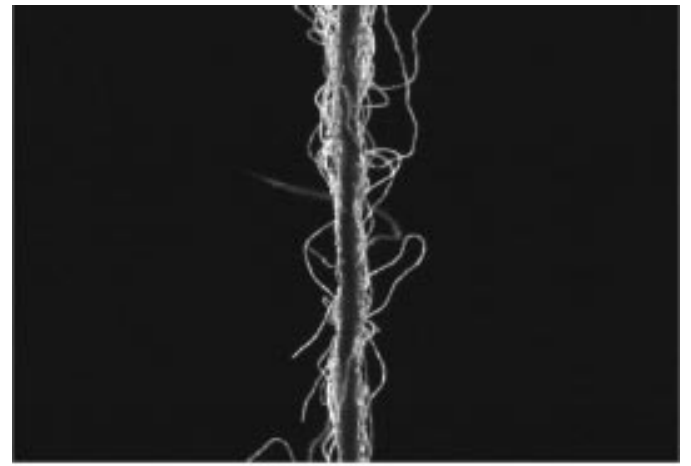

(a)

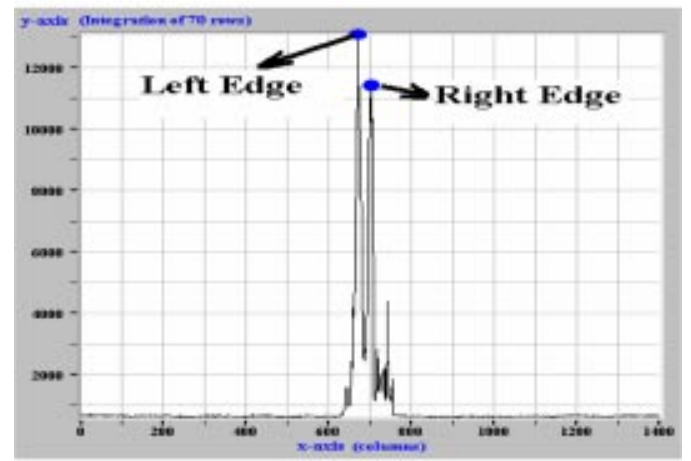

(b)

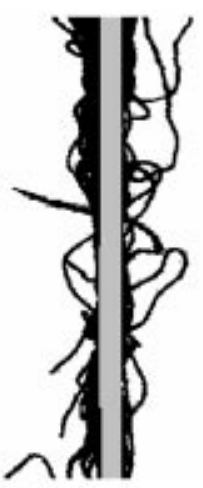

(c)

Fig. 15 (a) Dark-field yarn image, (b) integration of a $1 \mathrm{~mm}$ section for each column on a dark-field image showing the selection of core edges, (c) and (a) after hair-core background separation.

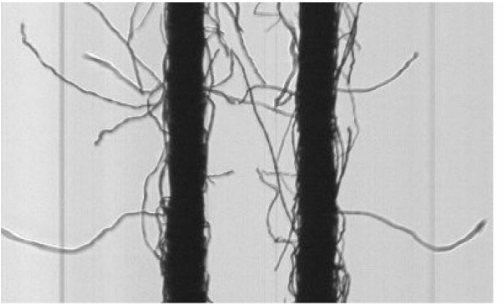

(a)

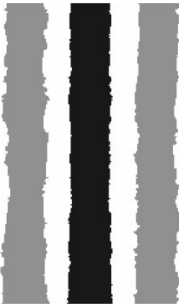

(b)
Fig. 16 A two-orthogonal yarn image (a) before and (b) after processing.

Figures 13(a) and 13(b) show a faulty yarn section and the processed image. It can be seen that the algorithm only allows a certain increase in the diameter creating triangular profiles at the core edges.

To overcome the problem, the regions on the yarn core that are affected from the filtering process are identified and successive filtered rows that correspond to more than $1 \mathrm{~mm}$ yarn length are reprocessed with no filtering and identified as a yarn fault. The fault length and the average diameter within the faulty region are then calculated. Figure 13(c) shows the filtered regions in a yarn image. In Fig. 13(d), a fault is shown as identified by the algorithm. This technique probably provides a better measure of the fault lengths compared to conventional optical sensors since a fault can start at any point in the yarn and can be at any length. If the diameter was to be measured using a conventional sensor say with $2 \mathrm{~mm}$ resolution, a fault with $1 \mathrm{~mm}$ length falling into a $2 \mathrm{~mm}$ section would be identified as being twice the length and half the magnitude. If the faulty section falls in the middle of two successive $2 \mathrm{~mm}$ sections, this effect would be more. Such a problem would not occur in the developed method.

\section{Processing of Dark-Field Yarn Images}

Yarn images under dark-field illumination do not exhibit a bimodal histogram since there are three major regions in the image arising from the background, hairs, and the core. Therefore, pre-processing algorithms developed for back-lit images cannot be applied for dark-field yarn images. In order to separate the background from yarn pixels, a threshold value of 25 is found suitable after examination of the background intensities when no yarn was present. It is not found necessary to use an adaptive method to find this threshold value, since the background intensity is not affected from the intensity of the light source as in the backlit illumination case. Figure 14 shows a dark-field image before and after applying this threshold.

The basic principle of the core-hair separation method developed for dark-field images is to integrate 70 rows (corresponding to $1 \mathrm{~mm}$ yarn section at 1:1 scanning aspect ratio) along every column and then to find the core edges from the obtained profile. Figure 15(b) shows a typical profile obtained by integrating 70 rows along each column in a dark-field image. It can be seen from this profile that there are two major peaks arising from the surface hairs on the left- and right-hand sides of the core. The processing algorithm automatically locates these two peaks and the left and right edges of the core are taken as the columns corre- 
Table 2 Specifications of the yarn samples.

\begin{tabular}{|c|c|c|c|c|c|c|c|c|c|}
\hline \multirow{2}{*}{$\begin{array}{l}\text { Sample } \\
\text { number }\end{array}$} & \multirow[b]{2}{*}{ Blend } & \multirow[b]{2}{*}{ Count } & \multirow{2}{*}{$\begin{array}{l}\text { Twist } \\
(\mathrm{T} / \mathrm{m})\end{array}$} & \multirow[b]{2}{*}{ Color } & \multicolumn{5}{|c|}{ Tests* } \\
\hline & & & & & 1 & 2 & 3 & 4 & 5 \\
\hline 1 & $65 / 35$ cotton/polyester & $\mathrm{Ne} 30 / 1$ (Tex 20/1) & 850 & Undyed & $\bullet$ & & - & - & \\
\hline 2 & $100 \%$ cotton & $\mathrm{Ne} 10 / 1$ (Tex 59/1) & 485 & Undyed & $\bullet$ & & $\bullet$ & $\bullet$ & \\
\hline 3 & $100 \%$ cotton & $\mathrm{Ne} 10 / 1$ (Tex 59/1) & 410 & Undyed & $\bullet$ & & $\bullet$ & $\bullet$ & \\
\hline 4 & $65 / 35$ cotton/polyester & $\mathrm{Ne} 30 / 1$ (Tex 20/1) & 779 & Undyed & $\bullet$ & & $\bullet$ & $\bullet$ & \\
\hline 5 & $65 / 35$ polyester/cotton & $\mathrm{Ne} 20 / 1$ (Tex 30/1) & 633 & Undyed & $\bullet$ & & $\bullet$ & $\bullet$ & \\
\hline 6 & $65 / 35$ polyester/cotton & $\mathrm{Ne} 10 / 1$ (Tex 59/1) & 448 & Undyed & $\bullet$ & & $\bullet$ & $\bullet$ & \\
\hline 7 & $65 / 35$ cotton/polyester & Ne 10/1 (Tex 59/1) & 485 & Undyed & - & & $\bullet$ & $\bullet$ & \\
\hline 8 & $100 \%$ cotton & $\mathrm{Ne} 10 / 1$ (Tex 59/1) & 448 & Undyed & $\bullet$ & $\bullet$ & - & $\bullet$ & ○ \\
\hline 9 & $65 / 35$ polyester/cotton & $\mathrm{Ne} 10 / 1$ (Tex 59/1) & 484 & Undyed & $\bullet$ & & $\bullet$ & $\bullet$ & \\
\hline 10 & 60/40 acrylic/wool & Nm 30/1 (Tex 33/1) & 480 & Black & $\bullet$ & & $\bullet$ & $\bullet$ & \\
\hline 11 & 60/40 acrylic/wool & Nm 30/1 (Tex 33/1) & 380 & Red & $\bullet$ & $\bullet$ & $\bullet$ & $\bullet$ & $\bullet$ \\
\hline 12 & $100 \%$ cotton & $\mathrm{Ne} 10 / 1(\operatorname{Tex} 59 / 1)$ & 435 & Undyed & $\bullet$ & $\bullet$ & $\bullet$ & $\bullet$ & $\bullet$ \\
\hline 13 & $100 \%$ cotton & $\mathrm{Ne} 20 / 1(\operatorname{Tex} 30 / 1)$ & 600 & Undyed & $\bullet$ & $\bullet$ & $\bullet$ & $\bullet$ & $\bullet$ \\
\hline 14 & $100 \%$ cotton & $\mathrm{Ne} 30 / 1(\operatorname{Tex} 20 / 1)$ & 770 & Purple & $\bullet$ & $\bullet$ & $\bullet$ & $\bullet$ & ○ \\
\hline 15 & $100 \%$ cotton & $\mathrm{Ne} 30 / 1$ (Tex 20/1) & 880.4 & Red & $\bullet$ & $\bullet$ & $\bullet$ & $\bullet$ & $\bullet$ \\
\hline 16 & $100 \%$ cotton & $\mathrm{Ne} 30 / 1(\operatorname{Tex} 20 / 1)$ & 864.4 & Gray & $\bullet$ & $\bullet$ & $\bullet$ & $\bullet$ & 0 \\
\hline 17 & $100 \%$ cotton & $\mathrm{Ne}$ 18/1 (Tex 33/1) & - & Undyed & • & $\bullet$ & $\bullet$ & - & 0 \\
\hline 18 & $100 \%$ cotton & $\mathrm{Ne} 12 / 1$ (Tex 49/1) & - & Undyed & $\bullet$ & $\bullet$ & $\bullet$ & $\bullet$ & $\bullet$ \\
\hline 19 & $100 \%$ cotton & $\mathrm{Ne} 30 / 1(\operatorname{Tex} 20 / 1)$ & - & Undyed & $\bullet$ & $\bullet$ & $\bullet$ & $\bullet$ & $\bullet$ \\
\hline 20 & $100 \%$ cotton & $\mathrm{Ne} 28 / 1(\operatorname{Tex} 21 / 1)$ & - & Undyed & $\bullet$ & $\bullet$ & $\bullet$ & $\bullet$ & $\bullet$ \\
\hline
\end{tabular}

1: back-lit single view, 2: dark field, 3: back-lit two orthogonal views, 4: premier 7000, 5: UT4.

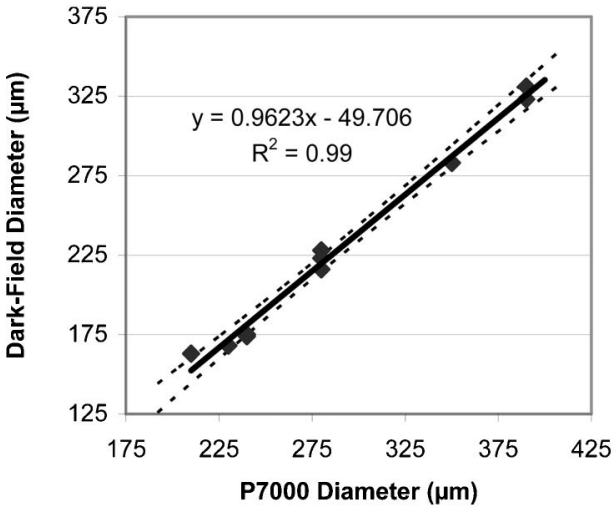

(a)

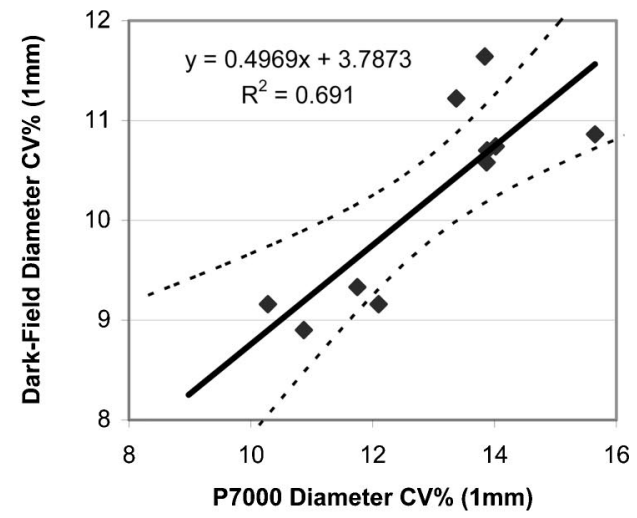

(b)

Fig. 17 Comparison of dark-field diameter and CVd\% values with P7000 tester (the dotted curves show the 95\% confidence bands).

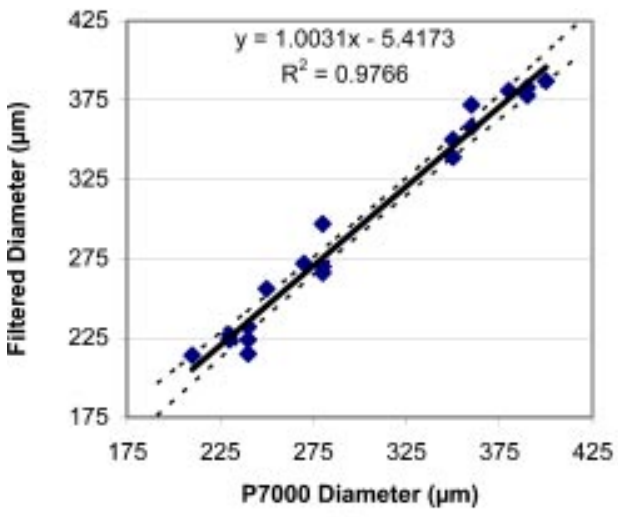

(a)

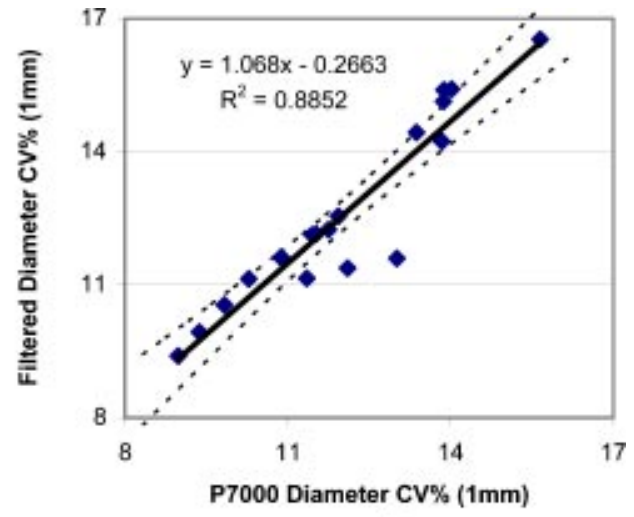

(b)

Fig. 18 Comparison of back-lit diameter and CVd\% values with P7000 tester (the dotted curves show the 95\% confidence bands). 
Table 3 Test results.

\begin{tabular}{|c|c|c|c|c|c|c|c|c|c|c|}
\hline $\begin{array}{l}\text { Sample } \\
\text { number }\end{array}$ & 1 & 2 & 3 & 4 & 5 & 6 & 7 & 8 & 9 & 10 \\
\hline P7000 diameter $(\mu \mathrm{m})$ & 230 & 380 & 400 & 240 & 250 & 360 & 360 & 390 & 350 & 270 \\
\hline P7000 diameter CV\% (1 mm) & 11.45 & 10.92 & 11.93 & 11.52 & 11.35 & 9.37 & 9.83 & 11.75 & 8.98 & 13.01 \\
\hline Dark field diameter $(\mu \mathrm{m})$ & & & & & & & & 331 & & \\
\hline DF Cvd (1 mm) & & & & & & & & 9.33 & & \\
\hline Back-lit filtered diameter $(\mu \mathrm{m})$ & 227 & 381 & 387 & 232 & 256 & 372 & 358 & 383 & 350 & 272 \\
\hline Back-lit non-filtered diameter & 233 & 397 & 406 & 240 & 265 & 384 & 368 & 398 & 358 & 279 \\
\hline Back-lit filtered Cvd (1 mm) & 12.12 & 11.57 & 12.54 & 12.14 & 11.14 & 9.93 & 10.54 & 12.24 & 9.39 & 11.59 \\
\hline Back-lit non-filtered CV (1 mm) & 13.61 & 12.63 & 13.79 & 13.72 & 12.58 & 11.48 & 11.63 & 13.33 & 10.29 & 16.65 \\
\hline Elliptical diameter $(\mu \mathrm{m})$ elliptical & 236 & 399 & 428 & 243 & 260 & 378 & 378 & 411 & 370 & 290.0 \\
\hline Elliptical diameter CV\% (1 mm) & 12.24 & 11.42 & 12 & 12.12 & 11.15 & 9.83 & 9.84 & 11.6 & 9.27 & 12.09 \\
\hline Diameter $(\mu \mathrm{m})$ from single view & 13.6 & 12.84 & 14.17 & 13.53 & 13.38 & 11.73 & 11.29 & 13.22 & 10.6 & 14.1 \\
\hline Diameter CV\% (1 mm) from single view & 230 & 393 & 421 & 237 & 256 & 371 & 371 & 404 & 361 & 289 \\
\hline USTER mass CV\% (8 mm) & & & & & & & & 12.84 & & \\
\hline Dark field diameter CV\% (8 mm) & & & & & & & & 8.65 & & \\
\hline Back-lit diameter CV\% (8 mm) & 11.02 & 10.87 & 11.53 & 11.05 & 10.51 & 8.8 & 9.31 & 11.21 & 8.59 & 12.42 \\
\hline Elliptical diameter CV\% (8 mm) & 10.14 & 9.78 & 10.22 & 9.82 & 9.09 & 8.29 & 8.26 & 10.02 & 7.69 & 10.94 \\
\hline $\begin{array}{l}\text { Sample } \\
\text { number }\end{array}$ & 11 & 12 & 13 & 14 & 15 & 16 & 17 & 18 & 19 & 20 \\
\hline P7000 diameter $(\mu \mathrm{m})$ & 280 & 390 & 280 & 240 & 240 & 230 & 280 & 350 & 210 & 240 \\
\hline P7000 diameter CV\% (1 mm) & 13.37 & 13.84 & 10.87 & 13.87 & 14.02 & 13.88 & 15.65 & 12.1 & 10.28 & 13 \\
\hline Dark field diameter $(\mu \mathrm{m})$ & 228 & 323 & 216 & 174 & 175 & 168 & 223 & 283 & 163 & 173 \\
\hline DF Cvd (1 mm) & 11.22 & 11.64 & 8.9 & 10.58 & 10.74 & 10.7 & 10.86 & 9.16 & 9.16 & 10.52 \\
\hline Back-lit filtered diameter $(\mu \mathrm{m})$ & 297 & 378 & 270 & 215 & 224 & 224 & 266 & 339 & 214 & 231 \\
\hline Back-lit non-filtered diameter & 313 & 394 & 281 & 222 & 234 & 234 & 274 & 356 & 221 & 238 \\
\hline Back-lit filtered Cvd (1 mm) & 14.43 & 14.23 & 11.61 & 15.13 & 15.41 & 15.39 & 16.53 & 11.37 & 11.13 & 11.60 \\
\hline Back-lit non-filtered CV (1 mm) & 16.65 & 15.58 & 13.19 & 17.01 & 17.53 & 17.85 & 18.53 & 13.07 & 12.52 & 12.65 \\
\hline Elliptical diameter $(\mu \mathrm{m})$ Elliptical & 321.0 & 412 & 299 & 233 & 237 & 241 & 282 & 364 & 218 & 243 \\
\hline Elliptical diameter CV\% (1 mm) & 11.81 & 14.23 & 11.54 & 15.44 & 15.47 & 15.43 & 16.02 & 12.19 & 10.61 & 16.01 \\
\hline Diameter $(\mu \mathrm{m})$ from single view & 14.16 & 15.97 & 14.13 & 17.95 & 18.25 & 18.29 & 17.92 & 14.38 & 12.95 & 18.08 \\
\hline Dia. CV\% (1 mm) from single view & 325 & 404 & 297 & 227 & 231 & 236 & 275 & 356 & 213 & 243 \\
\hline USTER mass CV\% (8 mm) & & 14.16 & 10.85 & 16.15 & 14.37 & 14.74 & 18.14 & 12.41 & 12.27 & 15.54 \\
\hline Dark field diameter CV\% (8 mm) & & 9.24 & 8.03 & 9.26 & 9.87 & 9.88 & 9.99 & 8.27 & 8.42 & 9.78 \\
\hline Back-lit diameter CV\% (8 mm) & 12.14 & 13.33 & 10.57 & 13.55 & 13.93 & 14.16 & 14.59 & 11.54 & 10.35 & 14.29 \\
\hline Elliptical diameter CV\% (8 mm) & 10.48 & 11.98 & 9.41 & 12.65 & 11.92 & 11.98 & 13.71 & 9.85 & 8.74 & 13.04 \\
\hline
\end{tabular}

sponding to these maximum points. Figure 15(c) shows a dark field image after hair-core background separation process.

\section{Processing of Two-Orthogonal Images}

The processing of two orthogonal images is almost the same as that used for processing the back-lit images. The core boundaries are found for each orthogonal view and an elliptical diameter is found from the left and right diameters $d_{l}$ and $d_{r}$ by taking the square root of their product. Figure 16 shows a two-orthogonal image before and after processing. The gray parts in the processed image are the extracted core regions for two orthogonal views, whereas the black part in the center is generated using the elliptical diameters for each row. It can be seen from the picture that the elliptical diameter is more uniform than the diameter from single side views.

\section{Results and Discussion}

A series of tests were carried out using 20 ring spun yarn samples shown in Table 2 using dark-field and back-lit illuminations and two-orthogonal imaging. For each setup 1250 images corresponding to a $25 \mathrm{~m}$ yarn length were stored in the computer for the analysis. This length was found adequate following the observation of change in average diameter and diameter variation for increasing test lengths which were stabilized after a test length of around $10 \mathrm{~m}$ for all samples. For real-time storing of the images, the test speed was kept low at $5 \mathrm{~m} / \mathrm{min}$. The results are compared with those from a Premier 7000 diameter tester and a Uster Tester 3 (UT3) irregularity tester. Only 100\% cotton yarn samples are considered for the comparisons with UT3 mass variation values. Dark-field imaging setup is also tested on $100 \%$ cotton samples as shown in Table 2. Figure 17 shows the comparison of diameter and diameter 

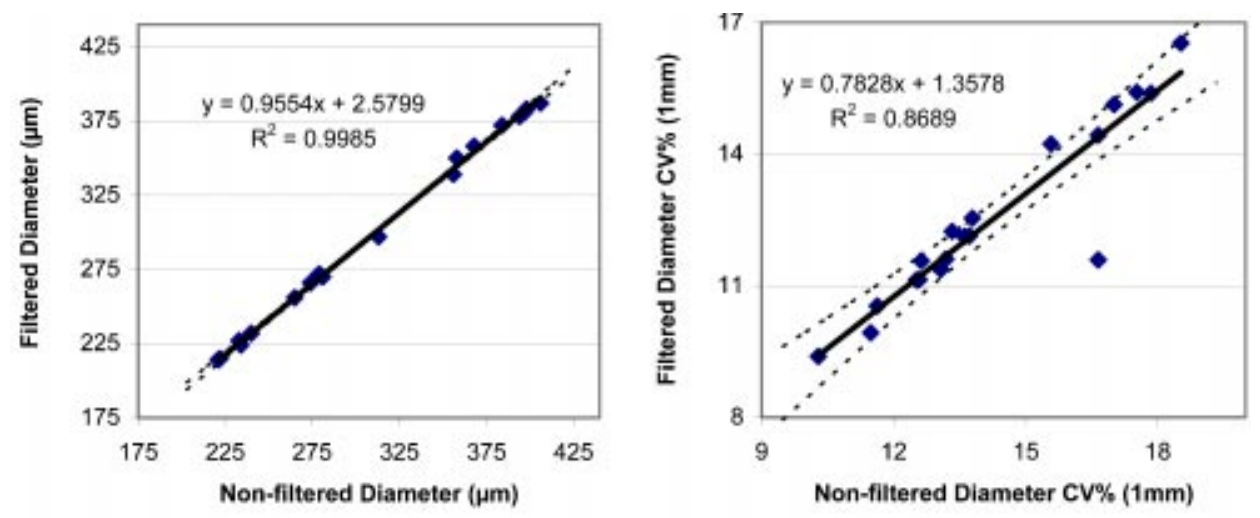

Fig. 19 Comparison of back-lit diameter and CVd\% values obtained with and without filtering the core data (the dotted curves show the $95 \%$ confidence bands).

variation values obtained using dark-field illumination with the measurements from P7000. The diameter CV\% values $(\mathrm{CVd} \%)$ are calculated for $1 \mathrm{~mm}$ sampling length as in P7000. It can be seen that, although there is a very good linear relation $\left(R^{2}=0.99\right)$ for diameter measurements there is an offset of about $50 \mu \mathrm{m}$ favoring the P7000 diameter values. The reason for this is most likely to be due to the difference in definition of the core boundaries in back-lit and dark-field illuminations, where the surface fibers covering the core account for the core in back-lit illumination whereas identified as hairs in dark-field illumination. The $\mathrm{CVd} \%$ values obtained from dark-field images exhibited a poor correlation $\left(R^{2}=0.69\right)$ with $\mathrm{P} 7000$ diameter $\mathrm{CVd} \%$ values. $\mathrm{P} 7000$ gave significantly higher $\mathrm{CVd} \%$ values for all of the samples. This again is probably due to definition of core boundaries in dark-field images, where there is a constant contribution to diameter from surface fibers which is likely to decrease the overall variation.

Figures 18(a) and 18(b) show the comparison of diameter and $\mathrm{CVd} \%$ values, respectively, from back-lit illumination and P7000. Almost a perfect linear relation with an $R^{2}$ value of 0.98 is found between diameter measurements from two testers and the measurements were of the same order of value as can be seen from Table 3. The variation values from two testers were also of the same order of value exhibiting a significant relation with an $R^{2}$ value of 0.84 .

The effect of the core filtering process described in the previous section can be seen in Fig. 19 where the comparison of diameter and $\mathrm{CVd} \%$ values obtained with and without filtering are given. It can be seen that the filtering process decreases the diameter by around $4 \%$ for all yarns. The $\mathrm{CVd} \%$ values are also decreased by around $23 \%$. However, the CVd\% of one particular yarn (No. 10) seems to be affected more severely from the filtering process than the other samples. This was found due to dense surface hairs present on the yarn. The $\mathrm{P} 7000 \mathrm{CVd} \%$ value of this yarn was in better agreement with the filtered $\mathrm{CVd} \%$ value.

The average diameters calculated from one and two orthogonal views exhibited almost the same values as shown in Fig. 20. The CVd\% values on the other hand, were higher for single views. This shows that the ellipticity of the yarn is not very important in diameter measurement due to the fact that the yarn is viewed at thin and thick sides with the same probability and the resulting average diameter is similar to the elliptical diameter for long test lengths. However, this randomness of thin and thick sides viewed by the camera brings about an increase in the diameter

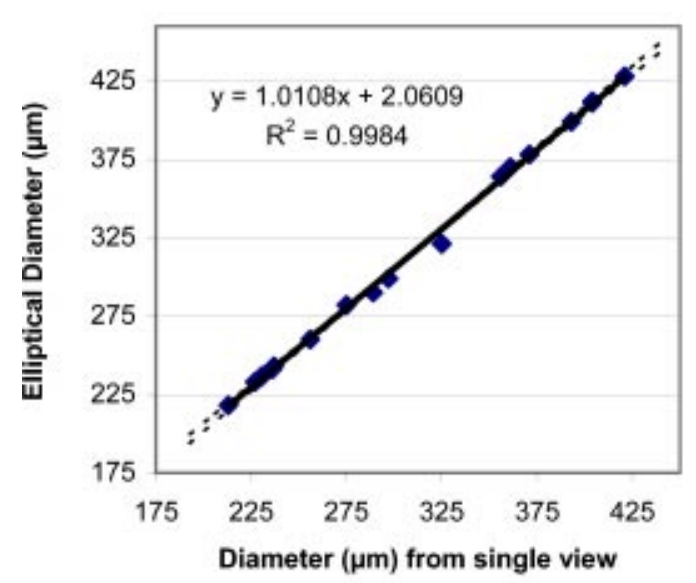

(a)

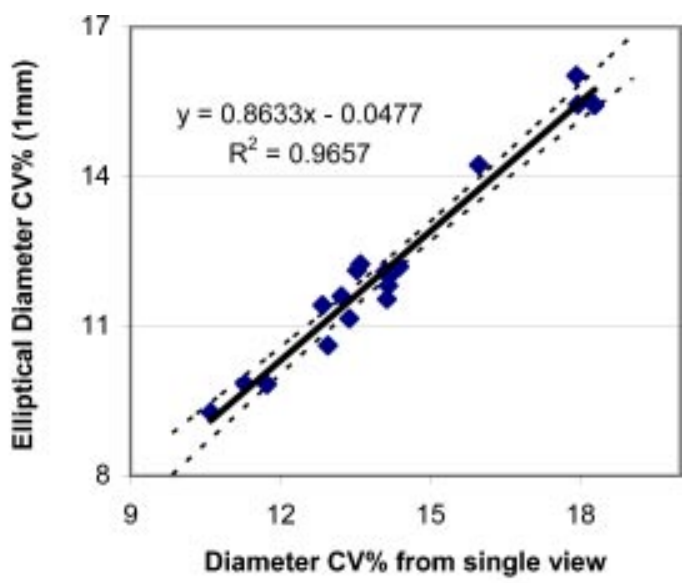

(b)

Fig. 20 Comparison of diameters from single view with elliptical diameter (the dotted curves show the 95\% confidence bands). 


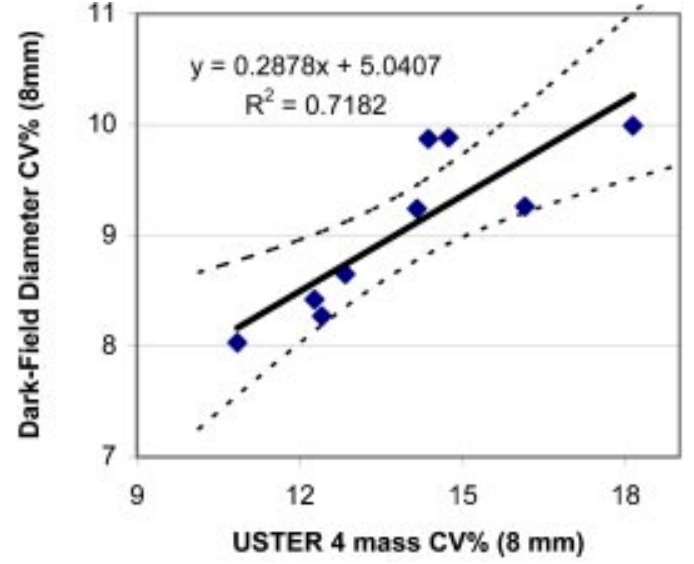

(a)

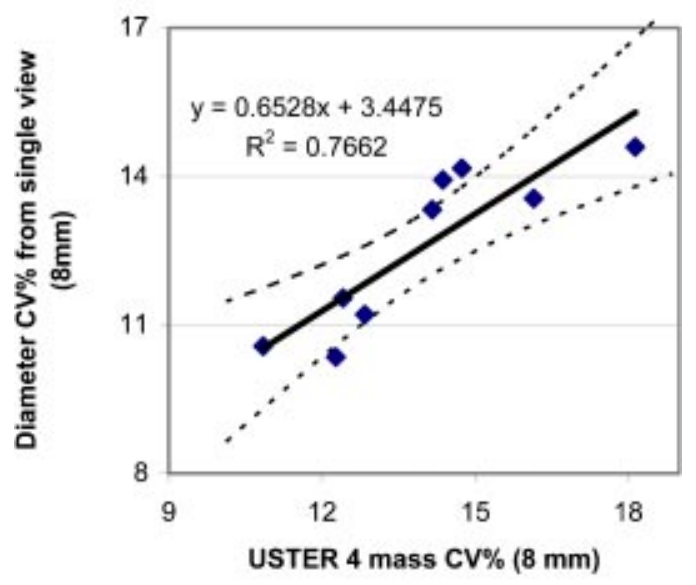

(b)

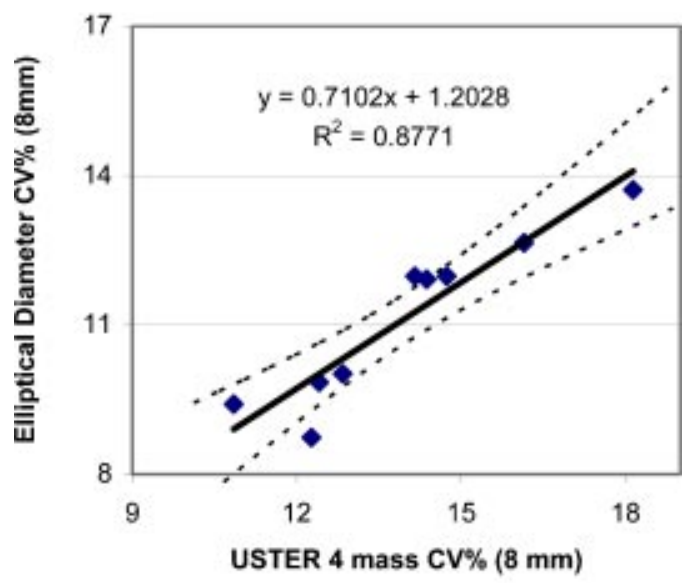

(c)

Fig. 21 Comparison of Uster CVm\% values with $\mathrm{CVd} \%$ values from different illumination methods for $8 \mathrm{~mm}$ sampling lengths (the dotted curves show the $95 \%$ confidence bands).

variation compared to the variation of elliptical diameter.

Figure 21 shows the comparison of $\mathrm{CVd} \%$ values obtained from different illumination methods for $8 \mathrm{~mm}$ sampling length with UT3 CVm\% values. In the comparisons only $100 \%$ Cotton yarn samples are considered. For darkfield images, the variations are calculated from diameters calculated as described in Sec. 4, but for $8 \mathrm{~mm}$ sections. The comparison of the dark-field $\mathrm{CVd} \%$ values and Uster $\mathrm{CVm} \%$ values is given in Fig. 21(a). Although the overall correlation exhibited an $R^{2}$ of 0.73 , an important offset of nearly 5 is seen favoring the dark-field $\mathrm{CVd} \%$ values. Further, by observing the scattering of the points on the graph, a different trend can be seen for some samples. These samples are $8,12,15,16,18$, and 19 . Nevertheless, a larger set of data is required for verification and explanation of these trends. The back-lit $\mathrm{CVd} \%$ values were in a better agreement with UT3 $\mathrm{CVm} \%\left(R^{2}=0.77\right)$ with an offset of 3.2 as shown in Fig. 21(b). There were again different trends for different samples as in the dark-field case. The correlation between UT3 CVm\% and the elliptical diameter $\mathrm{CV} \%$ values on the other hand was quite reasonable with an $R^{2}$ of 0.87 and almost zero offset as shown in Fig. 21(c). This verifies that the elliptical diameter has a better relation with the linear density compared to the diameter from single view.

\section{Conclusions}

The back-lit illumination is found superior compared to the dark-field illumination setup described in the paper in terms of depth of field tolerance and allowable shutter speeds. Different adaptive thresholding algorithms commonly used in the literature are tested and evaluated for back-lit yarn images. Global thresholding methods are found to fail in classifying either the defocused hairs or the isolated background pixels. Locally adaptive thresholding methods are found quite time consuming for a real-time application. Further, the local methods based on statistical calculations within small neighborhoods are seen to alter the yarn image classifying the core region as the background. A simple two level adaptive thresholding method is introduced that enables correct classification of defocused hairs and isolated background pixels around the core. Image processing techniques for hair-core separation are described for back-lit and dark-field images.

The yarn diameters are found to be smaller from darkfield images compared to back-lit images. The diameter and diametric variation data exhibited a very good correlation with the measurements from a Premier 7000 diametric irregularity tester. The diameter variation measured from back-lit images for $8 \mathrm{~mm}$ sampling length also exhibited a reasonable correlation with the mass variation measured on Uster Tester 3 for $100 \%$ cotton samples. The average diameter measurements obtained from the elliptical diameter are found to be in perfect agreement with those from single views. However the diametric variations were significantly lower in the former case. Further, the diametric variations obtained from two orthogonal views exhibited a better correlation with UT3 mass variations compared to single-side diameter variations.

\section{Acknowledgments}

This project has been sponsored by Loughborough University Mechanical Engineering Department. The authors would also like to thank both the Istanbul Technical University Textile Engineering Department for providing the yarn samples and North Carolina State University College of Textiles for enabling the use of yarn testing facilities. 


\section{References}

1. K. Slater, Yarn Evenness, Textile Progress 14 (3-4), The Textile Institute, Manchester (1986).

2. W. Soll, "Information gain through optoelectronic measurement of the two-dimensionally determined yarn diameter," Zellweger Uster Tester 4 Application Report (2000).

3. W. J. Onions and M. Yates, "The photoelectric measurement of the irregularity and the hairiness of worsted yarn," J. Text. Inst. 45(11), T873-885 (1954).

4. Zweigle Textilprufmaschinen, “OASYS® Measuring System,” http:// www.zweigle.com/index.html (2002).

5. Premier Polytronics Pvt. Ltd., "iQ QualiCenter datasheet," available at http://www.premier-1.com (2003).

6. A. Barella, "New concepts of yarn hairiness," J. Text. Inst. 47(2), 120-127 (1956).

7. B. E. van Issum and N. H. Chamberlain, "The free diameter and specific volume of textile yarns," J. Text. Inst. 50(11), T599-623 (1959).

8. F. Francini and G. Longobardi, "Quality control of textile yarn by optical filtering technique," Opt. Lasers Eng. 10(2), 119-126 (1989).

9. F. C. Rodrigues, M. S. Silva, and C. Morgado, "The configuration of a textile yarn in the frequency space: A method of measurement of hairiness," J. Text. Inst. 74(4), 161-169 (1983).

10. Keisokki Kogyo Co. Ltd., Keisokki Report (1997).

11. W. C. Chu and I. Tsai, "A new photoelectric device for the measurement of yarn diameter and yarn evenness. Part I: Improvement of the variance of radiant intensity using the area compensation method," $J$. Text. Inst. 87(3), 484-495 (1996).

12. B. Wulfhorst and J. Bergmann, "Comparison of different optical measuring methods for the determination of the real yarn diameter," $\mathrm{Mel}$ liand English 70, E41-E42 (1989).

13. W. C. Chu and I. Tsai, "A new photoelectric device for the measurement of yarn diameter and yarn evenness. Part II: The measurement of yarn diameter and the effect of shape-error factor (SEF) on the measurement of yarn evenness," J. Text. Inst. 87(3), 496-508 (1996).

14. A. Barella and A. Viaplana, "Principles of a new procedure for measuring yarn hairiness. Application to the study of the hairiness of open-end yarns," Text. Res. J. 40(3), 267-272 (1970).

15. A. Barella, V. Martin, J. P. Vigo, and A. M. Manich, "A new hairiness meter for yarns," J. Text. Inst. 71(6), 277-283 (1980).

16. M. Cybulska, "Assessing yarn structure with image analysis methods," Text. Res. J. 69(5), 369-373 (1999).

17. Y. A. Ozkaya, M. Acar, and M. R. Jackson, "Computer vision for yarn characterisation," Proc. of the 8th United Kingdom Mechatronics Forum Int. Conf. (2002).

18. L. M. Vas, G. Halász, M. Takács, I. Eördögh, and K. Szász, "Measurement of yarn diameter and twist angle with image processing system," Periodica Polytechnica Ser. Mech. Eng. 38(4), 277-296 (1994).

19. M. W. Suh, W. Jasper, J. L. Woo, and H. B. Kim, "Methods for fusing diameter and mass measurements of spun yarns," EFS System Research Forum, Raleigh, North Carolina (2000).

20. E. R. Riddle and W. R. Davis, "Successive optical measurements of cotton fiber-yarns and their analysis to obtain structural information including density and density variations," EFS System Research Forum $(2000)$.

21. J. Lappage and W. J. Onions, "An instrument for the study of yarn hairiness," J. Text. Inst. 55(8), T381-395 (1964).

22. P. Bamforth, M. R. Jackson, and K. Williams, "High accurracy automated scalloping of decorative lace," Proc. of the 8th United Kingdom Mechatronics Forum Int. Conf. (2002).

23. Y. A. Ozkaya, M. Acar, M. R. Jackson, and M. P. Millman, "Analysis of defocus aberration in yarn imaging," Proc. of the 9th United Kingdom Mechatronics Forum Int. Conf. (2004).

24. M. R. Jackson, M. Acar, L. Y. Siong, and D. Whitby, "A vision based yarn scanning system," Mechatronics 5(2/3), 133-146 (1995).

25. M. Millman, "Computer vision for yarn quality inspection," doctoral dissertation, Loughborough University, Loughborough (2000).

26. N. Otsu, "A threshold selection method from gray-level histograms,"
IEEE Trans. Syst. Man Cybern. T-SMC 9, 62-66 (1979).

27. J. Kittler and J. Illingworth, "Minimum error thresholding," Pattern Recogn. 19, 41-47 (1986).

28. J. N. Kapur, P. K. Sahoo, and A. K. C. Wong, "A new method for gray-level picture thresholding using the entropy of the histogram," Comput. Vis. Graph. Image Process. 29, 273-285 (1985).

29. A. S. Abutaleb, "Automatic thresholding of gray-level pictures using two-dimensional entropy," Comput. Vis. Graph. Image Process. 47, 22-32 (1989).

30. W. Niblack, An introduction to digital image processing, pp. 115-116, Prentice Hall, Englewood Cliffs, N.J. (1986).

31. J. Sauvola and M. Pietaksinen, "Adaptive document image binarization," Pattern Recogn. 33, 225-236 (2000).

32. J. Bernsen, "Dynamic thresholding of grey-level images," Proc. 8th Int. Conf. on Pattern Recognition (ICPR8), pp. 1251-1255 (1986).

33. S. D. Yanowitz and A. M. Bruckstein, "A new method for image segmentation," Comput. Vis. Graph. Image Process. 46(1), 82-95 (1989).

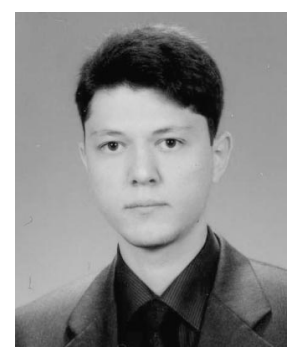

Yasar Alper Ozkaya received his BS degree in textile engineering from Istanbul Technical University in 1999 and his PhD degree in mechatronics from Loughborough University in 2004. His research interests are image processing, 2-D simulations and laser optics. He is currently working as a research associate at Loughborough University.

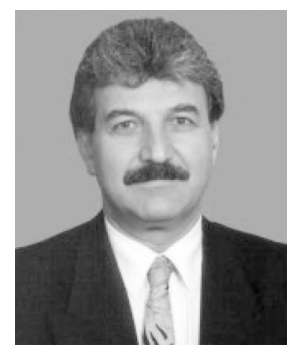

Memis Acar graduated from the Middle East Technical University (METU), Ankara, Turkey, with a BS degree in mechanical engineering in 1974. He obtained his MSc degree (textile technology) from the University of Manchester Institute of Science and Technology (UMIST) in 1979, and his PhD (mechanical engineering) from Loughborough University in 1984. His main research interests are biomechanics modeling and design for injury prevention and engineering processes using fibers and fibrous products. He has published over 100 professional journal and conference papers. He is a member of the Institution of Mechanical Engineers, American Society of Mechanical Engineers and Fiber Society. He is the present chairman of the United Kingdom Mechatronics Forum. He has held various positions at Loughborough University and is currently a senior lecturer since 1991.

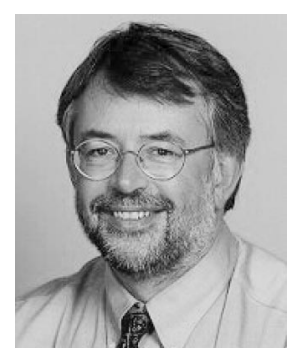

Mike Jackson received his $\mathrm{PhD}$ degree from Loughborough University. He has spent 17 years in industry on high speed machine tool design and research. His main interests are mechatronics and optical engineering. He is currently a senior lecturer at Loughborough University. 